\title{
Poly-cyclodextrin cryogels with aligned porous structure for removal of polycyclic aromatic hydrocarbons (PAHs) from water
}

\author{
Fuat Topuz $^{\mathrm{a}, *}$, Tamer Uyar ${ }^{\mathrm{a}, \mathrm{b}, * *}$ \\ a UNAM-National Nanotechnology Research Center, Bilkent University, 06800 Ankara, Turkey \\ ${ }^{\mathrm{b}}$ Institute of Materials Science E Nanotechnology, Bilkent University, 06800 Ankara, Turkey
}

\section{H I G H L I G H T S}

- Polycyclodextrin (polyCD) cryogels were successfully synthesized using PEG diepoxide cross-linkers.

- The cryogels displayed an aligned porous network structure due to the directional freezing of the matrix.

- The polyCD cryogels showed very high PAH sorption capacities varying between 105 and $1250 \mu \mathrm{g}$ per gram material.

- The materials could be recycled and reused without any significant loss in PAH adsorption capacity.

\section{A R T I C L E I N F O}

\section{Article history:}

Received 15 November 2016

Received in revised form 5 April 2017

Accepted 6 April 2017

Available online 7 April 2017

\section{Keywords:}

Cyclodextrin

Cryogel

Poly-cyclodextrin

PAH

Water remediation

\section{G R A P H I C A L A B S T R A C T}

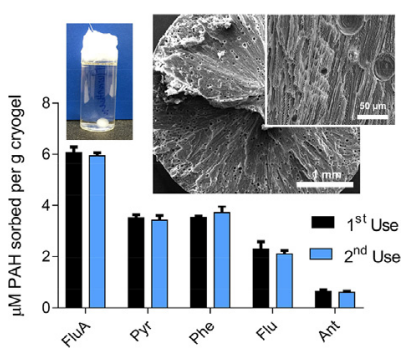

\begin{abstract}
A B S T R A C T
Cyclodextrins (CDs) are sugar-based cyclic oligosaccharides, which form inclusion complexes with small guest molecules through their hydrophobic cavity. Here we successfully synthesized highly porous poly-cyclodextrin (poly-CD) cryogels, which were produced under cryogenic conditions by the crosslinking of amine-functional CDs with PEG-based diepoxide cross-linker. The poly-CD cryogels showed aligned porous network structures owing to the directional freezing of the matrix, of which the pore size and architecture exposed variations depending on the composition of the reactants. The cryogels were employed for the removal of genotoxic polycyclic aromatic hydrocarbons (PAHs) from aqueous solutions. They reached PAH sorption capacities as high as $1.25 \mathrm{mg}$ PAH per gram cryogel. This high sorption performance is due to interactions between PAHs and the complete swollen network, and thus, is not restricted by interfacial adsorption. Given that the hydrophilic nature of the components, the sorption performance could only be attributed to the inclusion complex formation of CDs with PAH molecules. The poly-CD cryogels could be recycled with an exposure to ethanol and reused without any significant loss in the sorption capacity of PAHs.
\end{abstract}

(c) 2017 Elsevier B.V. All rights reserved.

\footnotetext{
* Corresponding author.

** Corresponding author at: UNAM-National Nanotechnology Research Center, Bilkent University, 06800 Ankara, Turkey.

E-mail addresses: fuat.topuz@rwth-aachen.de (F. Topuz),

tamer@unam.bilkent.edu.tr (T. Uyar).
}

\section{Introduction}

Cyclodextrins (CDs) are cyclic oligosaccharides produced by enzymatic conversion of starch. CDs have a distinct molecular structure like a truncated cone with a partially hydrophobic cavity, which allows non-covalent host-guest inclusion complexation with a large variety of hydrophobic molecules in water, and this complexation is triggered by enthalpic and entropic factors [1]. 
Native CDs $(\alpha-\mathrm{CD}, \beta$-CD and $\gamma$-CD) have certain limitations in the sense of their low water-solubility; the water solubility of $\alpha$-CD and $\gamma$-CD is about $145 \mathrm{~g} / \mathrm{L}$ and $232 \mathrm{~g} / \mathrm{L}$, respectively, while $\beta$-CD has the lowest water solubility $(18.5 \mathrm{~g} / \mathrm{L})$ amongst native CDs due to high number of intramolecular hydrogen bonds amongst secondary hydroxyl groups [2]. On the other hand, the chemically modified CDs, such as hydroxypropyl-CD and methylated-CD have much higher water solubility (above $600 \mathrm{~g} / \mathrm{L}$ ) [3]. Thus, numerous attempts have already been made towards the synthesis of watersoluble CD derivatives for functional material platforms [4-7]. In that context, amine-modified CDs have taken a considerable interest as they present accessible and highly reactive nucleophilic amines, which let further chemical ligations with various chemical groups under mild conditions. Particularly, using such aminemodified CDs for the synthesis of porous materials would be an interesting approach for a wide range of applications, including water remediation.

Cryogels are porous materials generated under cryogenic conditions, which take place in a non-frozen liquid of precursors existing in a macroscopically frozen sample [8]. These highly porous networks have been produced by either covalent or physical cross-linking of additives towards macroscopic platforms, which provides inter-linked pores along with surrounded thick polymer walls $[9,10]$. These platforms structurally mimic sponges with their inter-linked macroporous networks, and unlike their hydrogel analogues, such scaffolds offer many intrinsic benefits in terms of mechanical toughness (i.e., the ability of dissipate energy), a highly porous network structure, faster response, rapid water transport (water uptake and release) and many other structural benefits $[11,12]$. However, to the best of the authors' knowledge, to date there has been no study on a CD-based cryogel platform, which was prepared without using any polymer support.

PAHs are a large chemical family of fused benzene rings with their potent carcinogenic, teratogenic and mutagenic activities $[13,14]$. They are lipophilic compounds and ubiquitously present in water sources. Thus, they can accumulate on tissues, and exert its long-term effects in vivo. PAHs have potential to form PAH-DNA adducts after metabolic activation by cytochrome p450 enzymes, which lead to the genetic misleading, and therefore, they transform a normal cell into a cancer cell $[15,16]$. One important source of PAH uptake is polluted drinking water, particularly for developing countries, where they are often hampered by the lack of limited enforcement of water quality standards and available technologies for effective water-remediation. The long-term PAH exposure induces significant toxicity, and thus, several polymeric platforms have already been reported for the removal of PAHs (Table 1 ). Due to its unique cone-type structure that can form supramolecular complexes with guest molecules, CDs have been used as molecular traps to remove organic pollutants that are small enough to fit into the inner cavity of CD, such as PAHs [17,18]. Due to the water-solubility of CDs, their direct implementation as water filtering materials for the removal of pollutants from water is not practical. Therefore, CD-based platforms have been produced with appropriate crosslinking routes $[19,20]$, or functionalization or stabilization of CDs on solid materials [21-25].

In this paper, we synthesize poly-cyclodextrin (poly-CD) cryogels from amine-functional $\mathrm{CDs}$ and by its cryogenic gelation through poly(ethylene glycol) (PEG)-based diepoxide linkers towards functional materials with a highly porous network architecture. This process gradually happens because of low temperature along with lower kinetics, which causes slow cross-linking of CD molecules. Further, such cryogels present a hydrophilic material with hydrophobic $C D$ cavities, where each $C D$ cavity acts as a molecular trap for the entrapment of pollutants from aqueous systems. The cross-linker (i.e., poly(ethylene glycol) diglycidyl ether, PEG-DGE) is a hydrophilic compound, and it will thus not inter- fere with hydrophobic pollutants over hydrophobic associations so that the total removal of pollutants could only be attributed to the inclusion-complex formation with organic pollutants. Beyond the novelty of the synthesized poly-CD cryogel, this study also reveals the sorption performance of poly-CD cryogels, particularly for the removal of genotoxic polycyclic aromatic hydrocarbons (PAHs), with the advantage of having a highly porous hydrophilic network for the water treatment. Various characterization tools were employed to elucidate the structure-property relationship of the cryogels. The poly-CD cryogels were later employed for the elimination of several PAH molecules from water, and the sorption capacities were calculated. The materials could be recycled with an ethanol exposure, and thereafter retreated with PAH solutions without showing any significant reduction in the PAH-sorption capacities.

\section{Experimental section}

\subsection{Materials}

PAH molecules (i.e., pyrene, anthracene, phenanthrene, fluorene and fluoranthene), methanol $(\mathrm{MeOH},>99 \%)$ and poly(ethylene glycol) diglycidyl ether (PEG-DGE, $M_{\mathrm{n}}=500 \mathrm{~g} / \mathrm{mol}$ ) were purchased from Sigma-Aldrich. 3-Aminoproyl trimethoxysilane (APTMS) was kindly provided from Evonik (Germany), and hydroxypropyl $\beta$ -

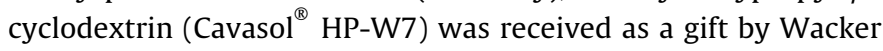
Co. (USA).

\subsection{Synthesis of amine-functional beta-cyclodextrins $\left(\mathrm{NH}_{2}-\beta-\mathrm{CDs}\right)$}

Amine-functional $\mathrm{CDs}\left(\mathrm{NH}_{2}-\beta\right.$-CDs) were synthesized through silane-hydroxyl reaction using an aminosilane coupler (3aminoproyl trimethoxysilane, APTMS) in methanol over 5 days. APTMS $(2 \mathrm{~mL})$ was mixed with HP- $\beta$-CD $(2 \mathrm{~g})$ in methanol $(100 \mathrm{~mL})$ under continuous stirring for 5 days. Thereafter, the solution was subjected to $90^{\circ} \mathrm{C}$ for $2 \mathrm{~h}$ and purified by precipitation in cold acetone. The product was dried at vacuum oven at $60^{\circ} \mathrm{C}$, and the $\mathrm{NH}_{2}-\beta$-CD was obtained as white powder. ${ }^{1} \mathrm{H}$ NMR spectra of the $\mathrm{NH}_{2}-\beta$-CD and $\mathrm{HP}-\beta-\mathrm{CD}$ were shown in Fig. 1.

The reaction of polysaccharides with silane molecules is previously reported, where the reaction proceeds between hydroxyls and silanol groups, forming silyl ether $(\mathrm{Si}-\mathrm{O}-\mathrm{C})$ links upon heat exposure [26,27]. This sol-gel process between silanes and various types of polysaccharides without the addition of an organic solvent and a catalyst led the jellification and the formation of monolithic hydrogels [27]. The solubility of native CDs in alcohols is considerably limited, and therefore, the synthesis was performed using soluble $\mathrm{CD}$ derivative, $\mathrm{HP}-\beta$-CD. The amine-modification of $\mathrm{HP}-\beta$ CD was performed by the silane-treatment in methanol over 5 days. As the CDs have some water content, so that silane groups were susceptible to slow hydrolysis to yield silanols ( $\mathrm{Si}-\mathrm{OH})$. Afterward, the solution subjected to $90^{\circ} \mathrm{C}$ for $2 \mathrm{~h}$. The heat-treatment for $2 \mathrm{~h}$ can drive the chemical conjugation between the silane and $C D$.

\subsection{Synthesis of macroporous poly-cyclodextrin (poly-CD) cryogels}

Amine-modified $\beta$-CD compounds were dissolved in water and thereafter mixed with PEG-DGE. The reaction took place between the epoxy group of PEGDGE and the amine group of the $\mathrm{NH}_{2}-\beta$ $\mathrm{CD}$ (see chemical structures of the reactants in Fig. S1). During the syntheses of the cryogels, the concentrations of both $C D$ and cross-linker (PEG-DGE) were systematically varied; the CD content boosted from 10 to $20 \%(\mathrm{w} / \mathrm{v}$ ) at the identical cross-linker concen- 
Table 1

Material systems used for the clean-up of PAHs from water.

\begin{tabular}{|c|c|c|c|c|c|c|}
\hline Material Composition & Material form & Material Polarity & Sorption mechanism & $\begin{array}{l}\text { Sorption capacity } \\
(\mu \mathrm{g} / \mathrm{g})\end{array}$ & Special features & Refs. \\
\hline Modified Silica & Gels & Apolar & Hydrophobic interactions & $200-300$ & Cytocompatible & Hall et al. [28] \\
\hline $\begin{array}{l}\text { Hemoglobin immobilized } \\
\text { on mesoporous silica }\end{array}$ & Particles & Apolar & Hydrophobic interactions & N.D. & Cytocompatible & Laveille et al. [29] \\
\hline Polyphenol & Particles & Apolar & $\begin{array}{l}\text { Hydrophobic } \\
\text { interactions, } \pi-\pi \\
\text { interactions }\end{array}$ & 750 & Required toxic $\mathrm{H}_{2} \mathrm{O}_{2}$ & Chen etal. [30] \\
\hline $\begin{array}{l}\text { Poly(ethylene } \\
\text { glycol)- } b \text {-poly(lactic } \\
\text { acid) (PEG- } b \text {-PLA) } \\
\text { copolymers }\end{array}$ & Nanoparticles & Polar-Apolar & Hydrophobic interactions & 310 & $\begin{array}{l}\text { Cytocompatible, problem } \\
\text { with scalability }\end{array}$ & Brandl et al. [31] \\
\hline $\begin{array}{l}\text { CD-functional cellulose } \\
\text { acetate }\end{array}$ & Fibers & Apolar-Polar & Hydrophobic interactions & 540 & Cytocompatible & Celebioglu et al. [25] \\
\hline Polypropylene & Fibers & Apolar & Hydrophobic interactions & 615 & Cytocompatible & Ceylan et al. [32] \\
\hline Poly-CD cryogels ${ }^{\mathrm{a}}$ & Macroporous gels & Polar & Host-guest & $105-1250$ & $\begin{array}{l}\text { Cytocompatible \& } \\
\text { Biodegradable }\end{array}$ & Present study \\
\hline Cyclophanes & Crystals & Apolar & $\begin{array}{l}\text { Donor-acceptor } \\
\text { interactions }\end{array}$ & N.D. & $\begin{array}{l}\text { Possible toxicity, } \\
\text { problem with scalability }\end{array}$ & Barnes et al. [33] \\
\hline Butyl rubber & Macroporous cryogels & Apolar & Hydrophobic interactions & 721 & Cytotoxic & Ceylan et al. [32] \\
\hline
\end{tabular}

N.D.; not determined.

a The present study.

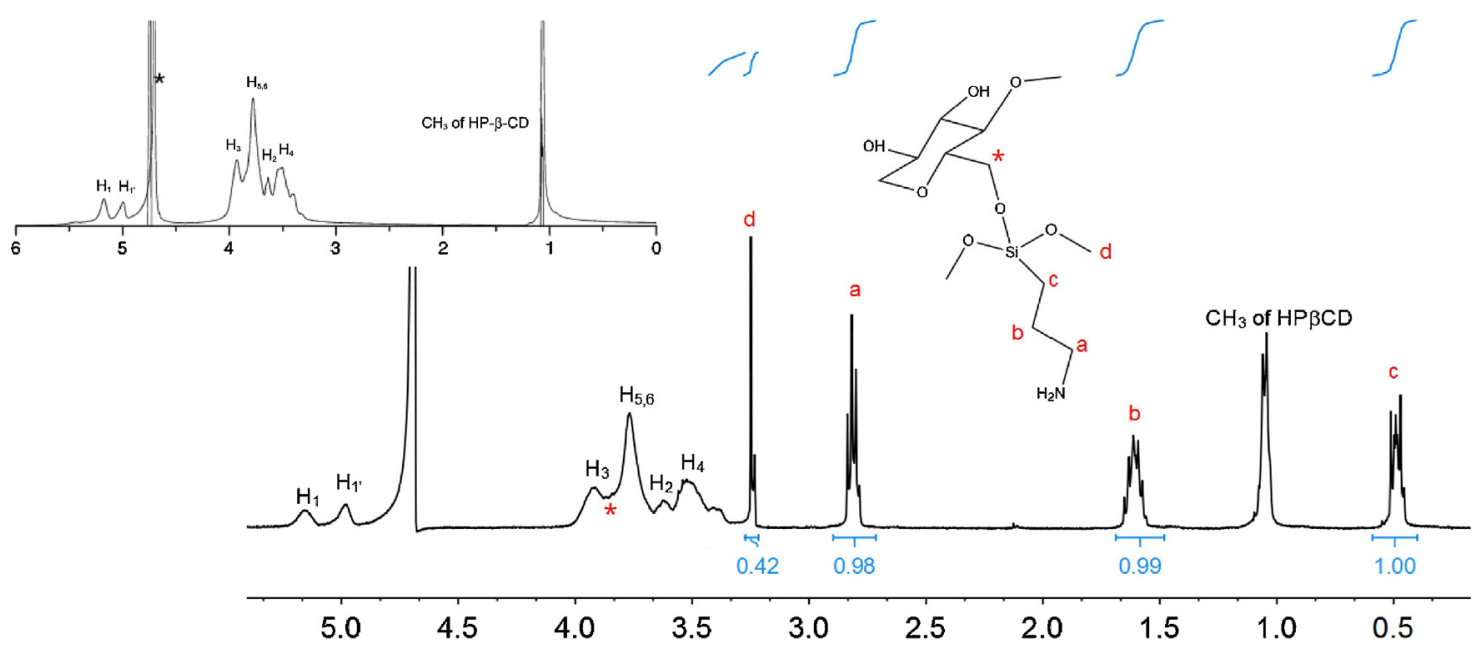

Fig. 1. ${ }^{1} \mathrm{H}$ NMR spectrum of the $\mathrm{NH}_{2}-\beta-\mathrm{CD}$ in $\mathrm{D}_{2} \mathrm{O}$. Inset shows the ${ }^{1} \mathrm{H}$ NMR of the HP- $\beta-\mathrm{CD}$.

tration $(0.35 \mathrm{mM})$, or the PEG-DGE content increased from 0.17 to $0.35 \mathrm{mM}$ at the constant CD content at 20\% (w/v). Thereafter, the solutions were transferred into plastic disposable syringes (inner diameter $(d)=4.7 \mathrm{~mm}$ ) and kept at $-20^{\circ} \mathrm{C}$ for the cross-linking reactions over 5 days. Following this procedure, the formation of highly opaque gels was observed. The gel samples were cut with a coldrazor blade and put in water for few hours to get rid of unbound precursors from the gel matrices. Following this procedure, the poly-CD cryogels were produced at various compositions of the precursors. The pore size distribution of the poly-CD crogels was estimated using Image software.

Fig. 2 illustrates the synthesis scheme of poly-CD cryogels, where both precursors $\left(\mathrm{NH}_{2}-\beta\right.$-CD and PEG-DGE) were mixed and exposed to liquid nitrogen and immediately kept at $-20^{\circ} \mathrm{C}$ to freeze water molecules towards ice crystals. This prompt freezing step was used to prevent undesired cross-linking reactions that can lead a hydrogel network. As the water molecules transformed into ice crystals, the concentrated $C D$ zones remained liquid districts areas in between. The $\mathrm{CD}$ aggregates gradually reacted towards a porous cross-linked matrix. This process was ended up with a sponge- like system with thick polymer walls, while inner matrix had an irregular inter-linked porous network.

\subsection{Characterization of materials}

FT-IR spectra of the dried poly-CD cryogels and $\mathrm{NH}_{2}-\beta$-CD powder were recorded using a Bruker-VERTEX 70 spectrometer. The spectra were taken at a resolution of $4 \mathrm{~cm}^{-1}$ with an accumulation of 128 scans.

The XPS spectra of the dried poly-CD cryogel samples were recorded by using an X-ray photoelectron spectrometer (Thermo Fisher Scientific, U.K.). As an X-ray source, Al K-alfa X-ray monochromator ( $0.1 \mathrm{eV}$ step size, $12 \mathrm{kV}, 2.5 \mathrm{~mA}$, spot size $400 \mu \mathrm{m})$ was used at an electron take-off angle of $90^{\circ}$. For each sample, survey spectrum was taken 5 times with $50 \mathrm{~ms}$ dwell time (pass energy $200 \mathrm{eV}$ ). All N1s, O1s, C1s and Si2p spectra were taken 10 times with $50 \mathrm{~ms}$ dwell time (pass energy $30 \mathrm{eV}$ ). The binding scale was referenced to the aliphatic component of $\mathrm{C} 1 \mathrm{~s}$ spectra at $284.85 \mathrm{eV}$.

${ }^{1} \mathrm{H}$ NMR spectra were recorded on a Bruker DPX-400 spectrometer at $400 \mathrm{MHz}$. The $\mathrm{NH}_{2}-\beta$-CD powder was dissolved in $\mathrm{D}_{2} \mathrm{O}$, and 

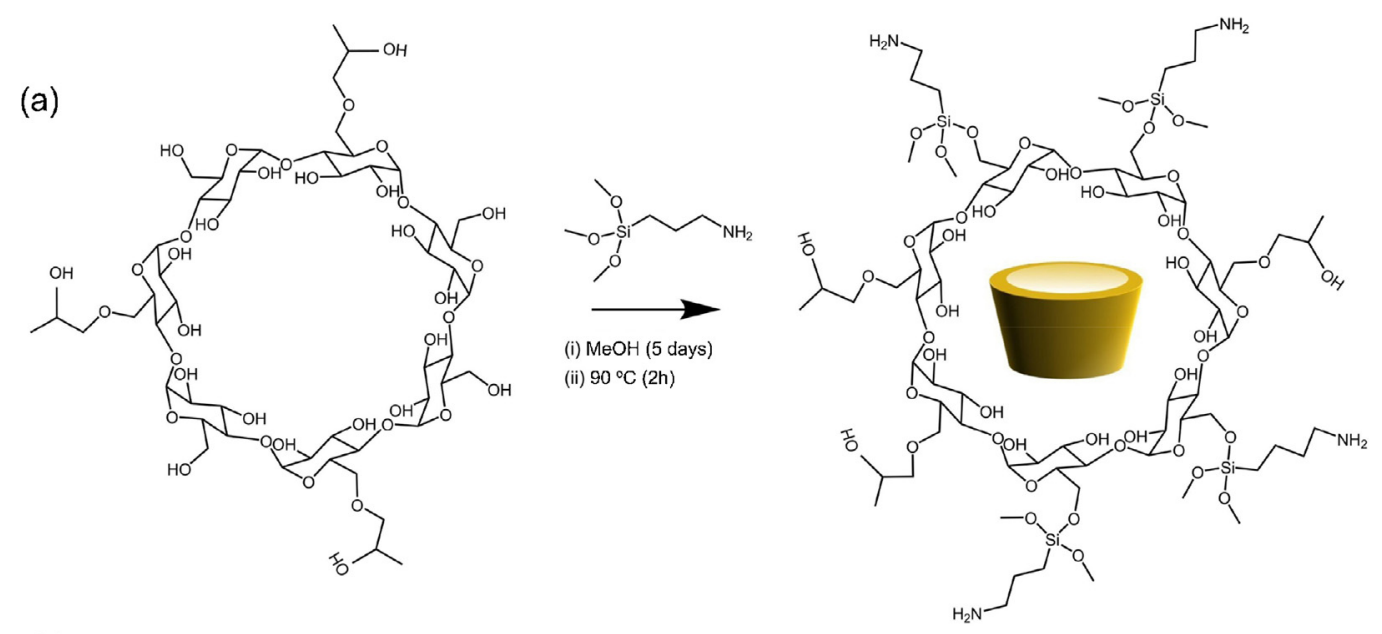

(b)

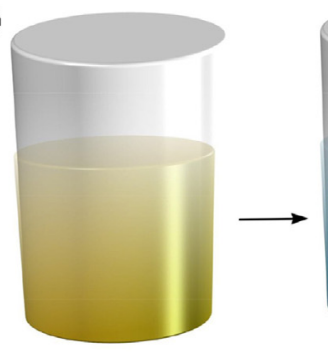

Cryogelation

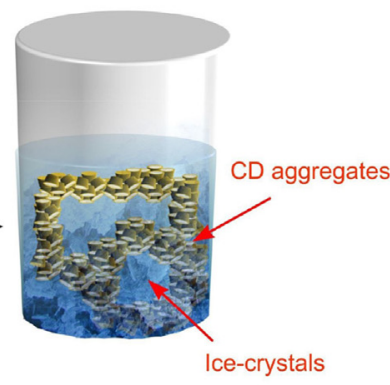

lce-crystals (c)

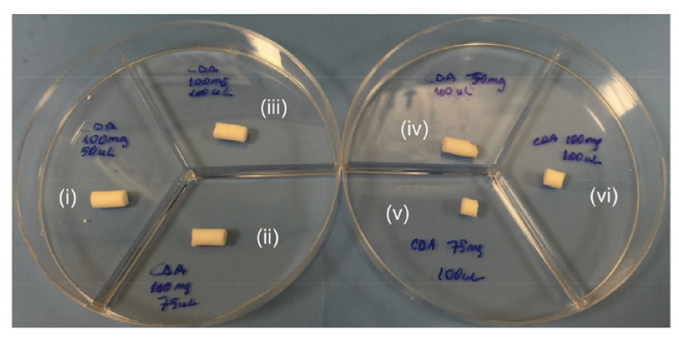

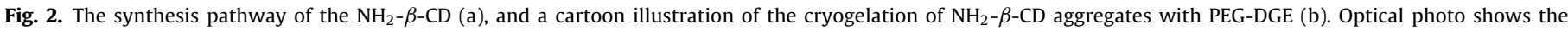

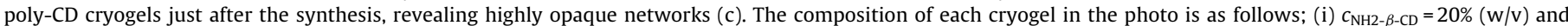

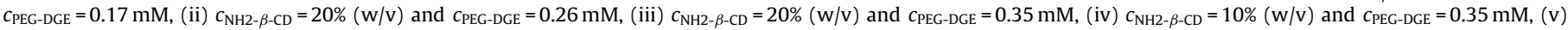
$c_{\mathrm{NH} 2-\beta-\mathrm{CD}}=15 \%(\mathrm{w} / \mathrm{v})$ and $c_{\mathrm{PEG}-\mathrm{DGE}}=0.35 \mathrm{mM}$, and $(\mathrm{vi}) c_{\mathrm{NH} 2-\beta-\mathrm{CD}}=20 \%(\mathrm{w} / \mathrm{v})$ and $c_{\mathrm{PEG}-\mathrm{DGE}}=0.35 \mathrm{mM}$.

the spectrum was recorded at $400 \mathrm{MHz}$ and 512 scans were performed.

For the molecular weight analysis of the $\mathrm{NH}_{2}-\beta$ - $\mathrm{CD}$, Agilent Technologies 6530 Accurate-Mass Q-TOF LC-MS and Zorbax SBC8 column were used. Solvents were water $(0.1 \%$ formic acid) and acetonitrile (ACN) ( $0.1 \%$ formic acid). LC-MS was run for $25 \mathrm{~min}$ for each sample, and it started with $2 \% \mathrm{ACN}$ and $98 \% \mathrm{H}_{2} \mathrm{O}$ for $5 \mathrm{~min}$. Afterward, ACN concentration reached to $100 \%$ for $20 \mathrm{~min}$. Thereafter, the concentration was dropped to $2 \%$, and it kept running for $5 \mathrm{~min}$. The solvent flow set to $0.65 \mathrm{~mL} / \mathrm{min}$, and $5 \mu \mathrm{L}$ sample was injected. $m / z$ : 1506, 1621.68, and 1742 .

The inner-morphology of the freeze-dried poly-CD cryogels was explored by SEM (Quanta 200 FEG, FEI) after gold-sputtering. The average pore diameter $(\langle D\rangle)$ and their distribution were calculated by analyzing ca. 100 pores from SEM images using ImageJ software (NIH, Bethesda, USA). Energy-dispersive X-ray (EDX) spectroscopy was used for monitoring the elemental composition of the material at $30 \mathrm{kV}$ and $4.5 \mathrm{~mA}$ on cupper tapes after gold-sputtering (Gatan 682 Precision and Coating System (PECS)).

Fluorescence spectra of the PAHs before and after treatments with the poly-CD cryogels were recorded on a Cary 100 fluorescence spectrophotometer using four-transparent faced quartz cuvettes. The excitation wavelengths were calculated using the maximum absorbance observed from UV-spectrum (Figs. S2-3). Emission wavelength range was from 260 to $600 \mathrm{~nm}$. The excitation wavelengths for PAHs are as follows: $260 \mathrm{~nm}$ (for phenanthrene), $264 \mathrm{~nm}$ (for fluoranthene), $250 \mathrm{~nm}$ (for anthracene), $260 \mathrm{~nm}$ (for pyrene) and $260 \mathrm{~nm}$ (for fluorene).

The adsorption spectra of the PAHs were gathered on a Cary 100 spectrophotometer. PAHs were dissolved in water, and the respective spectra were collected between 200 and $800 \mathrm{~nm}$ using two-transparent faced quartz cuvettes. The initial concentration of PAHs are respectively as follows: $0.20 \mu \mathrm{g} / \mathrm{mL}$ (for phenanthrene and pyrene), $0.40 \mu \mathrm{g} / \mathrm{mL}$ (for fluoranthene), $0.086 \mu \mathrm{g} / \mathrm{mL}$ (for fluorene) and $0.027 \mu \mathrm{g} / \mathrm{mL}$ (for anthracene).

\subsection{PAH sorption experiments}

PAH molecules (i.e., pyrene, anthracene, phenanthrene, fluorene and fluoranthene) were treated with the poly-CD cryogels $\left(c_{\mathrm{NH} 2-\beta-\mathrm{CD}}=20 \%(\mathrm{w} / \mathrm{v})\right.$ and $\left.\mathrm{C}_{\mathrm{PEG}-\mathrm{DGE}}=0.35 \mathrm{mM}\right)$ as a function of time (3, 6 and $9 \mathrm{~h}$ ). The cryogels were cut into cylindrical disks with a razor blade and transferred into an aqueous PAH solution $(20 \mathrm{~mL})$. The initial concentrations of PAHs are as follows: $0.20 \mu \mathrm{g} / \mathrm{mL}$ (for phenanthrene and pyrene), $0.40 \mu \mathrm{g} / \mathrm{mL}$ (for fluoranthene), $0.086 \mu \mathrm{g} / \mathrm{mL}$ (for fluorene) and $0.027 \mu \mathrm{g} / \mathrm{mL}$ (for anthracene). After shaking for 3,6 and $12 \mathrm{~h}$ at $25^{\circ} \mathrm{C}$ using a heat-controlled incubator (Fig. S4), $3 \mathrm{~mL}$ of this solution was transferred into vials and the fluorescence measurements were performed. $3 \mathrm{~mL}$ water was added to keep the total volume constant. Note that the cryogels remained as white cylindrical masses in vials such that the aqueous part could easily be taken out. Thus, no particular step was used to separate the cryogels from PAHs. The amount of cryogels (i.e. after the synthesis) used in each experiment varied between ca. 50 and $60 \mathrm{mg}$. The emission spectra of the respective PAH molecules after having treated with the poly-CD cryogels were recorded, and the sorption capacity for each PAH molecule was calculated using standard curves of the respective PAH molecule (Figs. S5-9), and the data have given per gram dry cryogel. The experiments were performed in triplicate, and the mean data were presented. 
Recyclability experiments were performed after an exposure to ethanol of $20 \mathrm{~mL}$ by three times over $5 \mathrm{~min}$ for each. Thereafter, the sample was treated with water $(20 \mathrm{~mL})$ for $10 \mathrm{~min}$. The amount of cryogels is similar to the material used for PAH sorption tests $(\sim 50 \mathrm{mg})$. Thereafter, the freshly prepared samples were treated again with PAH solutions within different time intervals, and the supernatant part was measured with a fluorescence spectrophotometer to monitor variations in PAH contents.

\section{Results and discussion}

The LC-MS spectrum of the product revealed the successful formation of amine-functional $\mathrm{CDs}\left(\mathrm{NH}_{2}-\beta\right.$ - $\left.\mathrm{CDs}\right)$, where the peaks related to the $\mathrm{NH}_{2}-\beta$-CDs appeared in the range of $1400-1900 \mathrm{~g} \mathrm{~mol}^{-1}$ (Fig. S10). Note that pristine HP- $\beta$-CD has an average molecular weight of $\sim 1400 \mathrm{~g} \mathrm{~mol}^{-1}$. Thus, the peaks appeared between 1400 and $1900 \mathrm{~g} \mathrm{~mol}^{-1}$ can be assigned to the silane conjugation. Interestingly, no dimer or trimer formation was oberved after the reaction. However, note that HP- $\beta$-CD is also a polydisperse molecule, and thus, its reaction with silanes leads to variations in the molecular weight of the product. The synthesis of the $\mathrm{NH}_{2}-\beta$-CD was further confirmed by ${ }^{1} \mathrm{H}$ NMR analysis, where the characteristic peaks of $C D$ protons were observed between 3 and $6 \mathrm{ppm}$ (Fig. 1). The presence of methyl protons bound silicon at $0.56 \mathrm{ppm}$ refers to the silane conjugation. ${ }^{1} \mathrm{H}$ NMR shows the methyl protons adjacent to the amine at $2.90 \mathrm{ppm}$, while the methyl protons of the propyl group of CDs appeared at $1.15 \mathrm{ppm}$. The protons of $\mathrm{CH}_{2}-\mathrm{CH}_{2}-\mathrm{NH}_{2}$ were observed as multiplet at $1.60 \mathrm{ppm}$. The XRD pattern of the $\mathrm{NH}_{2}-\beta$-CD revealed the amorphous structure as similar to HP- $\beta$-CD (Fig. S11).

Fig. 2 (inset) shows the optical photos of the poly-CD cryogels produced at various compositions of precursors. For all conditions, the formation of a cryogel matrix suggests that the cryogelation was successful at various concentrations of CD and PEG-DGE (Fig. 2, inset photo). On the other hand, no gel formation was observed in the absence of $C D$ moieties. All cryogels were opaque while maintaining their cylindrical forms, suggesting highly heterogeneous network structures. This opaqueness is an intrinsic characteristic of cryogel systems because of the network heterogeneity induced by irregular interlinked macropores. The water contents at freshly synthesized gel samples after freeze-drying were calculated in the range of $67-76 \%$ depending on the used precursor content, demonstrating that nearly all CDs were chemically bound to the scaffolds with corresponding gel fractions $\left(W_{\mathrm{g}}\right)$ over $0.98(98 \%)$.

The inner matrices of the cryogels were explored by scanning electron microscopy (SEM), revealed aligned macropores rather than irregular pores. Whereas, the gel surface displayed thickpolymer walls with collapsed pores (Fig. 3). This is due to the directional freezing of water, which led to the growth of ice crystals and the orientation from the surface to the interior. Generally, such a kind of pore structure requires particular freezing-setups, i.e., one-side of the chamber exposed to cooling with a so-called method "unidirectional freezing" [34-36]. The pore size distribution was shown in Fig. 3(f), where the mean pore size was calculated as $2.53 \mu \mathrm{m}$. The alignment of the pores could be ascribed to the directional freezing of water molecules on the way of the temperature gradient. This can also be seen on the orientation of the pores from the surface to the core (Fig. 3a). The pore size was directly affected by the concentration of the precursors. For instance, wellaligned pores were observed at high concentrations of $C D$ and cross-linker while lowering PEG-DGE concentration led to collapsed pores (Figs. 4 and S12). This might be attributed that once the concentration is high enough, the structural integrity of the matrix is preserved.

The atomic composition of the poly-CD cryogels, which were synthesized at various compositions of precursors, was studied by $\mathrm{X}$-ray photoelectron spectroscopy (XPS). Although XPS is mainly used for the compositional analysis of surfaces rather than the matrix, here the samples are homogenously formed by the mixed solution of the $\mathrm{NH}_{2}-\beta$-CD and PEG-DGE. Though the samples show
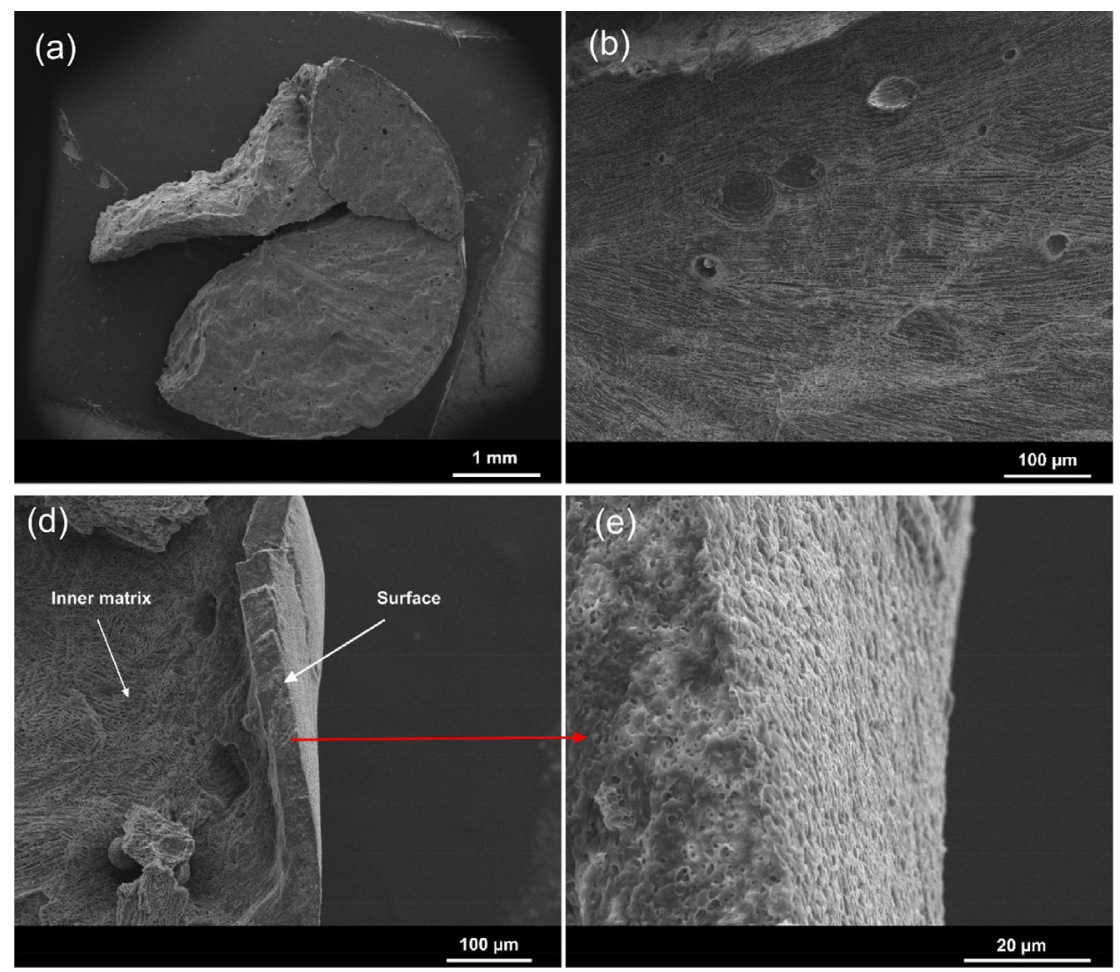

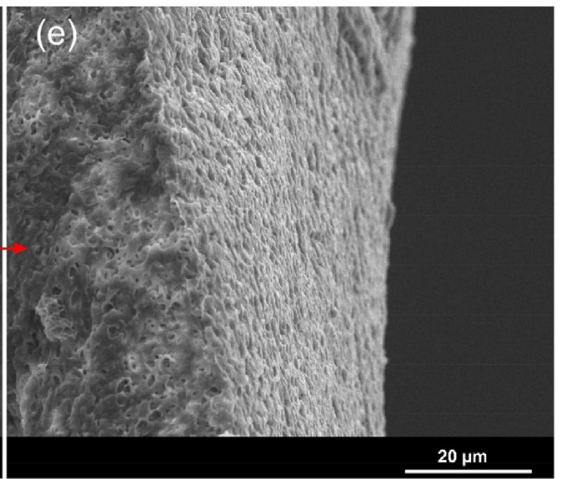

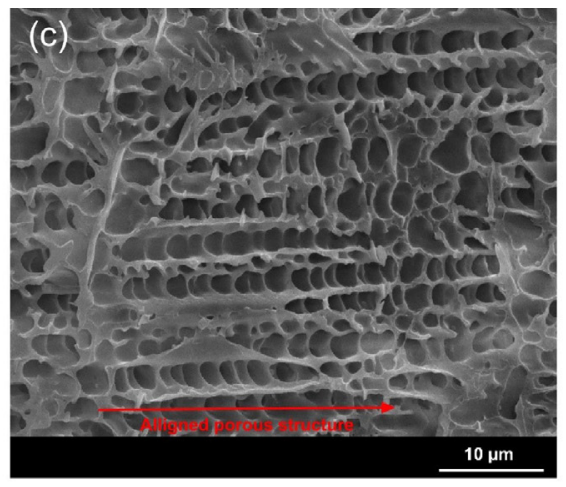

(f)

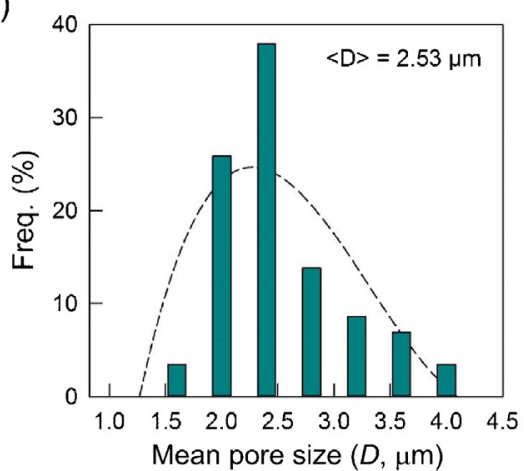

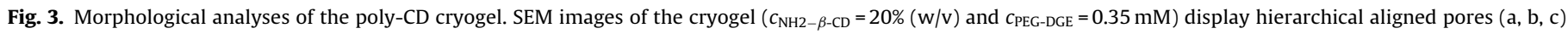
while the gel surface shows irregular collapsed pores ( $d, e)$. The pore-size distribution diagram of the poly-CD cryogel (f). 

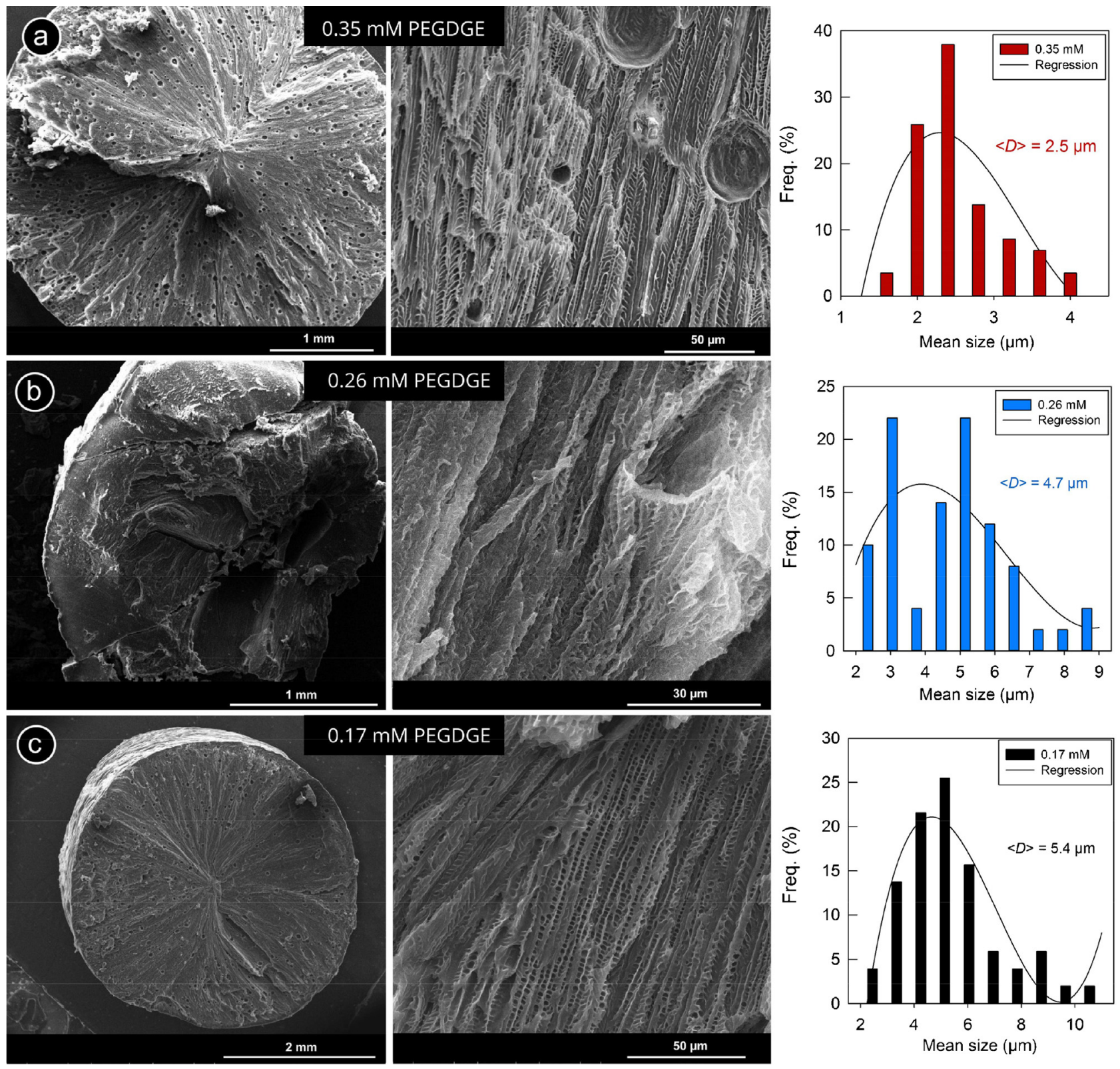

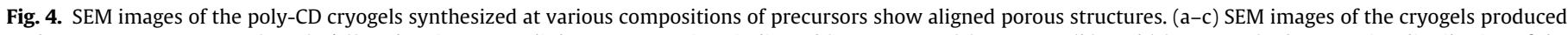

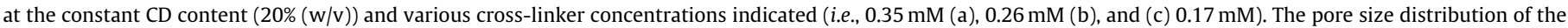
respective cryogel systems.

different pore architecture between the surface and inner matrix, it is not expected to have any significant variations in the chemical composition between the surface and matrix. Fig. 5 shows the XPS survey spectra of the cryogels where the cryogels were made up substantially by carbon (C) and oxygen (O) and subordinately nitrogen $(\mathrm{N})$ and silicon $(\mathrm{Si})$. The presence of the nitrogen $(\mathrm{N})$ and silicone $(\mathrm{Si})$ atoms could be attributed to the amine-modified CDs. With an increase of $C D$ ratio in the formulation of the cryogels, both $\mathrm{N}$ and Si contents substantially rise. Deconvoluted C1s spectra show that with an increase of $C D$, the $C-C$ carbon $(284.8 \mathrm{eV})$ peak rises, while the addition of more cross-linker induces a significant increase in $\mathrm{C}-\mathrm{O}$ peak $(286 \mathrm{eV})$ (Fig. S13). Note that the HP- $\beta$-CD has a high amount of $\mathrm{C}-\mathrm{O}$ bond, but after modification with silane moieties, its proportion decreases in the overall composition. On the other hand, the cross-linker PEG-DGE has considerable $\mathrm{C}-\mathrm{O}$ bonds, and thus, the increase of $C$ content could be attributed to higher cross-linker content. With an increase of the CD content by two-fold from 10 to $20 \%(\mathrm{w} / \mathrm{v})$, nitrogen $(\mathrm{N})$ content in the sample rises.

Table 2 summarizes the atomic compositions of the cryogels and as well as $\mathrm{NH}_{2}-\beta-\mathrm{CD}$ molecules. The $\mathrm{HP}-\beta-\mathrm{CD}$ has not any $\mathrm{N}$ and $\mathrm{Si}$, while the $\mathrm{NH}_{2}-\beta$-CD has considerable amounts of $\mathrm{N}$ and $\mathrm{Si}$. Therefore, the cryogels display considerable proportions of the respective elements in overall composition. The $\mathrm{N}$ content in the $\mathrm{NH}_{2}-\beta$-CD is about $5.84 \%$, while the Si content (as Si2s and $\mathrm{Si} 2 \mathrm{p}$ ) is found as $9.37 \%$, suggesting that $\mathrm{NH}_{2}$ functional $\mathrm{CD}$ molecules have substantial Si content. Thus, the material formed by the $\mathrm{NH}_{2}-\beta$ $\mathrm{CD}$ should also possess quantifiable amounts of both atoms ( $\mathrm{N}$ and $\mathrm{Si}$ ). With an increase of CD content from 10 to $20 \%$ (w/v), N content increases from 1.06 to 1.84 , while Si content rises from 3.94 to 6.68. On the other hand, with an increase of PEGDGE content by two-fold from 0.17 to $0.35 \mathrm{mM}, \mathrm{N}$ content decreases from 2.22 to $1.84 \%$. PEGDGE does not have any $\mathrm{Si}$ and $\mathrm{N}$ atoms while it has more $\mathrm{C}(64.68 \%)$ than the $\mathrm{O}(35.32 \%)$ (see Table 2 ). The chemical composi- 

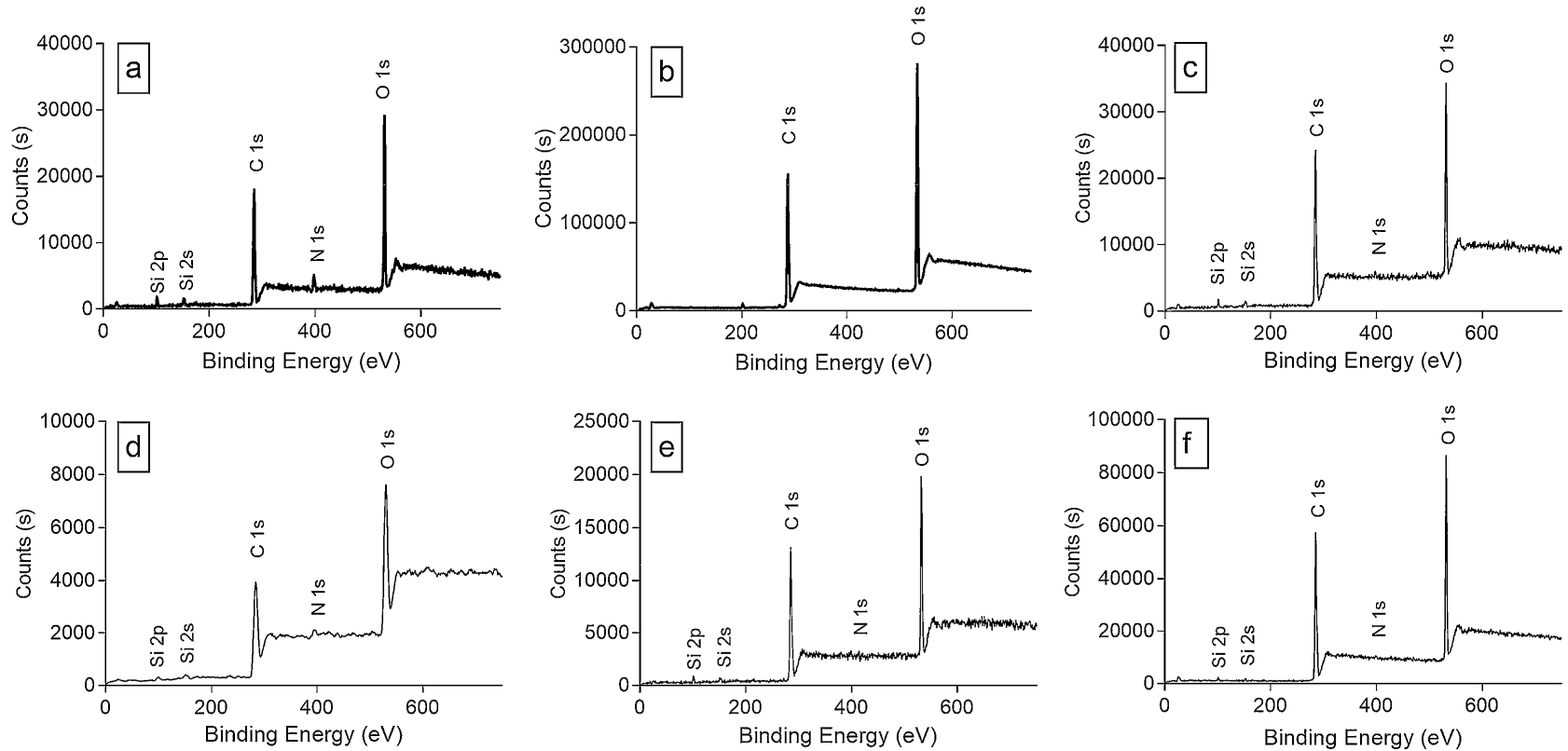

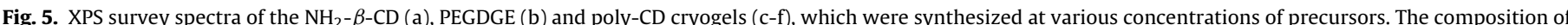

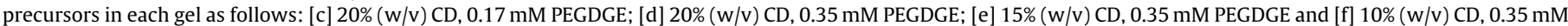
PEGDGE.

Table 2

XPS atomic compositions of the poly-CD cryogels, $\mathrm{NH}_{2}-\beta-\mathrm{CD}$ and PEG-DGE.

\begin{tabular}{|c|c|c|c|c|c|c|}
\hline & ${ }^{[a]} \mathrm{NH}_{2}-\beta-\mathrm{CD}$ & ${ }^{[b]}$ PEG-DGE & $\begin{array}{l}{ }^{[c]}(20 \%(\mathrm{w} / \mathrm{v}) \mathrm{CD} \\
-0.17 \mathrm{mM})\end{array}$ & $\begin{array}{l}{ }^{[d]}(20 \%(\mathrm{w} / \mathrm{v}) \mathrm{CD} \\
-0.35 \mathrm{mM})\end{array}$ & $\begin{array}{l}{ }^{[e]}(15 \%(\mathrm{w} / \mathrm{v}) \mathrm{CD} \\
-0.35 \mathrm{mM})\end{array}$ & $\begin{array}{l}{ }^{[f]}(10 \%(\mathrm{w} / \mathrm{v}) \mathrm{CD} \\
-0.35 \mathrm{mM})\end{array}$ \\
\hline $\mathrm{C} 1 \mathrm{~s}(285 \mathrm{eV})$ & 56.52 & 64.68 & 63.06 & 65.31 & 65.60 & 66.21 \\
\hline O1s (581 eV) & 28.77 & 35.32 & 28.21 & 26.17 & 29.63 & 29.79 \\
\hline N1s (399eV) & 5.84 & 0 & 2.22 & 1.84 & 0.90 & 1.06 \\
\hline $\mathrm{Si} 2 \mathrm{p}(101 \mathrm{eV})$ & 5.07 & 0 & 3.71 & 3.16 & 2.86 & 1.60 \\
\hline Si2s $(152 \mathrm{eV})$ & 4.30 & 0 & 2.81 & 3.52 & 1.01 & 1.34 \\
\hline
\end{tabular}

[a]-[f] denote to the sample numbers in Fig. 5.

tions of the cryogels were also analyzed by FT-IR, where the typical stretching peak of $\mathrm{C}-\mathrm{H}$ bond appeared at $2932 \mathrm{~cm}^{-1}$ (Fig. S14). A broad peak at $3408 \mathrm{~cm}^{-1}$ could be ascribed to the $\mathrm{O}-\mathrm{H}$ vibration, and but, it overlaps with $\mathrm{N}-\mathrm{H}$ vibration of primary and secondary amines. The $\mathrm{C}-\mathrm{H}$ stretching of epoxy ring should normally appear at $\sim 840$ and $910 \mathrm{~cm}^{-1}$, and both samples do not show any peak in the respective region, suggesting that epoxy rings reacted with amines. The reaction between epoxy and amine groups through a ring-opening mechanism led to a cross-linked gel network.

Fig. S15 (see Supporting Information) shows the PAH sorption performances of the cryogels after $6 \mathrm{~h}$ treatment, where significant reduction in the fluorescence intensity was observed for all PAH molecules. For some PAH molecules (pyrene, fluoranthene and phenanthrene), almost complete removal of PAHs was observed, for other PAHs (fluorene and anthracene), very small peaks associated residual PAHs were detected, suggesting the efficient removal of PAHs by poly-CD cryogels. Likewise, time-dependent PAH removal experiments revealed that the no significant variation was observed between 3 and 9 h treatments (Fig. 6). The fluorescence spectra of the PAHs after $3 \mathrm{~h}$ PAH treatment revealed a substantial decrease in the fluorescence intensity. Further increasing exposure time did not reduce the amount of trace PAHs.

The PAH-sorption capacities of the cryogels after $6 \mathrm{~h}$ treatment were shown in Fig. 7, where the samples show PAH scavenging capacities in the range of 0.6-6.22 $\mu \mathrm{M}$ PAH molecule per gram poly-CD cryogel. The highest sorption capacity was found for fluoranthene $(6.22 \mu \mathrm{M} / \mathrm{g}$ dry cryogel) while the lowest one was observed for anthracene $(0.59 \mu \mathrm{M} / \mathrm{g})$. The photo of the cryogel sample shows that the structural integrity of the material after $6 \mathrm{~h}$ treatment with fluoranthene. The sorption values are high enough and comparable to other good PAH scavenging material systems (Table 1), and further, this performance can be attributed to the complete network more than interfacial adsorption. The total removal of PAHs in percent was found over 94\%, suggesting the high efficiency of these materials in PAH removal (see Fig. 7, inset). The water-solubility range of the PAHs (i.e. phenanthrene, anthracene, fluorene, fluoranthene and pyrene) varies between 0.044 and $1.9 \mathrm{mg}$ per liter. Even though having less ring number, the water solubility of anthracene $(0.044 \mathrm{mg} / \mathrm{L})$ is much lower than the fluoranthene $(0.265 \mathrm{mg} / \mathrm{L})$. Since PAHs are poorly soluble compounds, very low amount of poly-CD cryogels could decrease their initial content up to $97 \%$.

One of the main advantages of the proposed system is its recyclability with an exposure to ethanol. The solubility of PAH in ethanol is much higher than its solubility in water. Thus, supramolecular complexes between PAHs and CDs will be broken due to the entropic reasons. The use of ethanol for the PAH separation from different sources, including soils was previously reported, where the ethanol treatment significantly reduced PAH concentration [37]. After ethanol exposure and the subsequent use of poly-CD cryogels, the materials revealed almost identical sorption performance for all PAH molecules (Fig. S16), suggesting the recyclability of the presented system. As the poly-CD gels are chemically cross-linked networks, ethanol exposure does not cause any substantial change on the material morphology. 

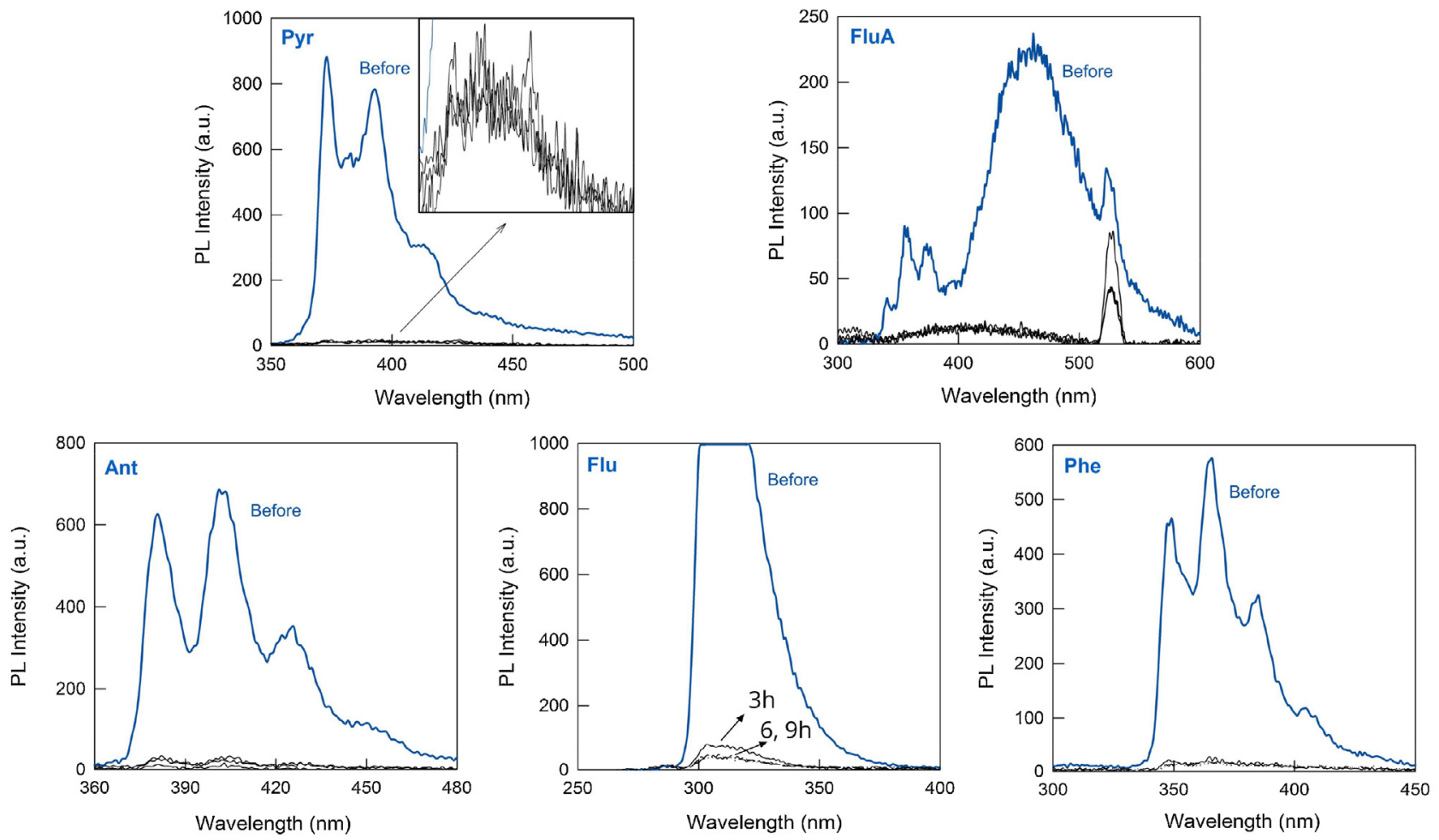

Fig. 6. Time-dependent fluorescence spectra of the PAHs before and after treatments with poly-CD cryogels for 3, 6 , and $9 \mathrm{~h}$ (black lines).

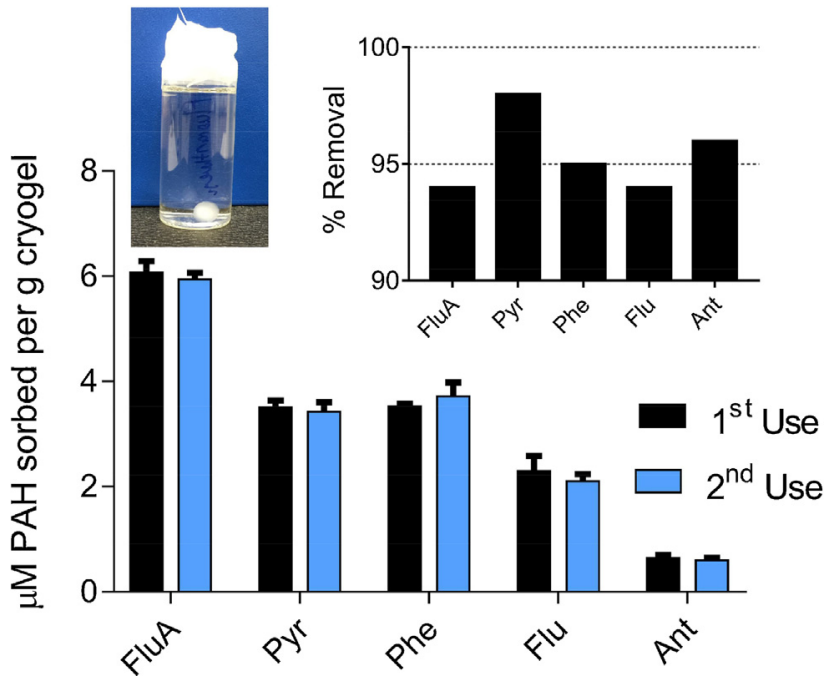

Fig. 7. The PAH sorption capacities of the poly-CD cryogels $\left(\mathrm{C}_{\mathrm{NH} 2-\beta-\mathrm{CD}}\right)=20 \%(\mathrm{w} / \mathrm{v})$ $\left.\& C_{\text {PEGDGE }}=0.35 \mathrm{mM}\right)$ after $1^{\text {st }}$ and $2^{\text {nd }}$ use. Inset shows the "Per cent $(\%)-$ Removal" of the respective PAH compounds. The inset photo shows the poly-CD cryogel after the $6 \mathrm{~h}$ treatment of fluoranthene.

\section{Conclusion}

The synthesis of CD-based cryogels through the cryogenic gelation of the $\mathrm{NH}_{2}-\beta$-CD with PEGDGE without using any polymer support was successfully shown. The fabricated gels possess an aligned porous network due to the directional freezing of the samples during the cross-linking of precursors under cryogenic conditions at which the pore architecture could be tailored by variations in the formulation parameters. The cryogels display relative high sorption capacities for the removal of PAH molecules (e.g., pyrene, anthracene, phenanthrene, fluorene and fluoranthene) within a range of $0.6-6 \mu \mathrm{M}$ PAH molecule per g poly-CD.
This high sorption performance is due to both interfacial adsorption and the volume-based scavenging mechanism. Further, the crosslinked network structure allows recycling the materials with an exposure to ethanol, and the materials could be used repeatedly without any significant loss in the sorption performance. Beside their use as a sorbent, such functional porous platforms also have high potential for drug delivery, where the CD cavities can act as drug carriers.

\section{Acknowledgements}

F. T. thanks to TUBITAK Co-Funded Brain Circulation Scheme (project number: 116C031). T. U. acknowledges The Turkish Academy of Sciences - Outstanding Young Scientists Award Program (TUBA-GEBIP)-Turkey for partial funding of the research. Authors thank to Dr. Kugalur S. Ranjith for the XPS analysis of PEG-DGE molecule.

\section{Appendix A. Supplementary data}

Supplementary data associated with this article can be found, in the online version, at http://dx.doi.org/10.1016/j.jhazmat.2017.04. 022 .

\section{References}

[1] M.V. Rekharsky, Y. Inoue, Complexation thermodynamics of cyclodextrins, Chem. Rev. 98 (1998) 1875-1918.

[2] J. Szejtli, Introduction and general overview of cyclodextrin chemistry, Chem. Rev. 98 (1998) 1743-1754.

[3] A. Zuorro, M. Fidaleo, R. Lavecchia, Solubility enhancement and antibacterial activity of chloramphenicol included in modified $\beta$-cyclodextrins, Bull. Korean Chem. Soc. 31 (2010) 3460-3462.

[4] A.M. O’Mahony, B.M.D.C. Godinho, J. Ogier, M. Devocelle, R. Darcy, J.F. Cryan, C.M. O'Driscoll, Click-modified cyclodextrins as nonviral vectors for neuronal siRNA delivery, ACS Chem. Neurosci. 3 (2012) 744-752.

[5] H. Bricout, F. Hapiot, A. Ponchel, S. Tilloy, E. Monflier, Chemically modified cyclodextrins: an attractive class of supramolecular hosts for the development of aqueous biphasic catalytic processes, Sustainability 1 (2009) 924. 
[6] A. Ueno, T. Kuwabara, A. Nakamura, F. Toda, A modified cyclodextrin as a guest responsive colour-change indicator, Nature 356 (1992) 136-137.

[7] R. Challa, A. Ahuja, J. Ali, R.K. Khar, Cyclodextrins in drug delivery: an updated review, AAPS PharmSciTech 6 (2005) E329-E357.

[8] V.I. Lozinsky, F.M. Plieva, I.Y. Galaev, B. Mattiasson, The potential of polymeric cryogels in bioseparation, Bioseparation 10 (2001) 163-188.

[9] T.M.A. Henderson, K. Ladewig, D.N. Haylock, K.M. McLean, A.J. O'Connor, Cryogels for biomedical applications, J. Mater. Chem. B 1 (2013) 2682-2695.

[10] G. Ertürk, B. Mattiasson, Cryogels-versatile tools in bioseparation, J. Chromatogr. A 1357 (2014) 24-35.

[11] V.I. Lozinsky, I.Y. Galaev, F.M. Plieva, I.N. Savina, H. Jungvid, B. Mattiasson, Polymeric cryogels as promising materials of biotechnological interest, Trends Biotechnol. 21 (2003) 445-451.

[12] F. Topuz, O. Okay, Macroporous hydrogel beads of high toughness and superfast responsivity, React. Funct. Polym. 69 (2009) 273-280.

[13] V.J. Melendez-Colon, A. Luch, A. Seidel, W.M. Baird, Cancer initiation by polycyclic aromatic hydrocarbons results from formation of stable DNA adducts rather than apurinic sites, Carcinogenesis 20 (1999) 1885-1891.

[14] J. van Grevenynghe, M. Bernard, S. Langouet, C. Le Berre, T. Fest, O. Fardel, Human CD34-positive hematopoietic stem cells constitute targets for carcinogenic polycyclic aromatic hydrocarbons, J. Pharmacol. Exp. Ther. 314 (2005) 693-702.

[15] K. Srogi, Monitoring of environmental exposure to polycyclic aromatic hydrocarbons: a review, Environ. Chem. Lett. 5 (2007) 169-195.

[16] G. Liu, Z Niu, D. Niekerk, J. Xue, L. Zheng Polycyclic aromatic hydrocarbons (PAHs) from coal combustion: emissions, analysis, and toxicology, in: D.M. Whitacre (Ed.), Reviews of Environmental Contamination and Toxicology, Springer New York, New York, NY, 2008, pp. 1-28.

[17] J. Wu, Z. Gong, L. Zheng, Y. Yi, J. Jin, X. Li, P. Li, Removal of high concentrations of polycyclic aromatic hydrocarbons from contaminated soil by biodiesel, Front. Environ. Sci. Eng. China 4 (2010) 387-394.

[18] C. Viglianti, K. Hanna, C. de Brauer, P. Germain, Removal of polycyclic aromatic hydrocarbons from aged-contaminated soil using cyclodextrins: experimental study, Environ. Pollut. 140 (2006) 427-435.

[19] B.B. Mamba, R.W. Krause, T.J. Malefetse, E.N. Nxumalo, Monofunctionalized cyclodextrin polymers for the removal of organic pollutants from water, Environ. Chem. Lett. 5 (2007) 79-84.

[20] N. Morin-Crini, G. Crini, Environmental applications of water-insoluble ß-cyclodextrin-epichlorohydrin polymers, Prog. Polym. Sci. 38 (2013) 344-368.

[21] G. Crini, M. Morcellet, Synthesis and applications of adsorbents containing cyclodextrins, J. Sep. Sci. 25 (2002) 789-813.

[22] T. Uyar, R. Havelund, Y. Nur, J. Hacaloglu, F. Besenbacher, P. Kingshott, Molecular filters based on cyclodextrin functionalized electrospun fibers, J. Membr. Sci. 332 (2009) 129-137.
[23] T. Uyar, R. Havelund, J. Hacaloglu, F. Besenbacher, P. Kingshott, Functional electrospun polystyrene nanofibers incorporating $\alpha-, \beta-$, and $\gamma$-cyclodextrins: comparison of molecular filter performance, ACS Nano 4 (2010) 5121-5130.

[24] F. Kayaci, Z. Aytac, T. Uyar, Surface modification of electrospun polyester nanofibers with cyclodextrin polymer for the removal of phenanthrene from aqueous solution, J. Hazard. Mater. 261 (2013) 286-294.

[25] A. Celebioglu, S. Demirci, T. Uyar, Cyclodextrin-grafted electrospun cellulose acetate nanofibers via Click reaction for removal of phenanthrene, Appl. Surf. Sci. 305 (2014) 581-588

[26] M. Abdelmouleh, S. Boufi, A. ben Salah, M.N. Belgacem, A. Gandini, Interaction of silane coupling agents with cellulose, Langmuir 18 (2002) 3203-3208.

[27] Y.A. Shchipunov, T.y.Y. Karpenko, Hybrid polysaccharide-silica nanocomposites prepared by the sol-gel technique, Langmuir 20 (2004) 3882-3887.

[28] S. Hall, R. Tang, J. Baeyens, R. Dewil, Removing polycyclic aromatic hydrocarbons from water by adsorption on silicagel, Polycycl. Aromat. Compd. 29 (2009) 160-183.

[29] P. Laveille, A. Falcimaigne, F. Chamouleau, G. Renard, J. Drone, F. Fajula, S. Pulvin, D. Thomas, C. Bailly, A. Galarneau, Hemoglobin immobilized on mesoporous silica as effective material for the removal of polycyclic aromatic hydrocarbons pollutants from water, New J. Chem. 34 (2010) 2153-2165.

[30] B. Chen, M. Yuan, H. Liu, Removal of polycyclic aromatic hydrocarbons from aqueous solution using plant residue materials as a biosorbent, J. Hazard. Mater. 188 (2011) 436-442.

[31] F. Brandl, N. Bertrand, E.M. Lima, R. Langer, Nanoparticles with photoinduced precipitation for the extraction of pollutants from water and soil, Nat. Commun. 6 (2015) 7765.

[32] D. Ceylan, S. Dogu, B. Karacik, S.D. Yakan, O.S. Okay, O. Okay, Evaluation of butyl rubber as sorbent material for the removal of oil and polycyclic aromatic hydrocarbons from seawater, Environ. Sci. Technol. 43 (2009) 3846-3852.

[33] J.C. Barnes, M. Juríček, N.L. Strutt, M. Frasconi, S. Sampath, M.A. Giesener, P.L. McGrier, C.J. Bruns, C.L. Stern, A.A. Sarjeant, J.F. Stoddart, A. ExBox, Polycyclic aromatic hydrocarbon scavenger, J. Am. Chem. Soc. 135 (2013) 183-192.

[34] J. Wu, Q. Zhao, J. Sun, Q. Zhou, Preparation of poly(ethylene glycol) aligned porous cryogels using a unidirectional freezing technique, Soft Matter 8 (2012) 3620-3626.

[35] V.A. Schulte, D.F. Alves, P.P. Dalton, M. Moeller, M.C. Lensen, P. Mela, Microengineered PEG hydrogels: 3D scaffolds for guided cell growth, Macromol. Biosci. 13 (2013) 562-572.

[36] I. Aranaz, M. Gutiérrez, M. Ferrer, F. del Monte, Preparation of chitosan nanocomposites with a macroporous structure by unidirectional freezing and subsequent freeze-drying, Mar. Drugs 12 (2014) 5619.

[37] B.-D. Lee, M. Hosomi, Ethanol washing of PAH-contaminated soil and Fenton oxidation of washing solution, J. Mater. Cycles Waste Manage. 2 (2000) 24-30. 